\title{
USOS LINGUÍSTICOS DE UM GRUPO DE LÉSBICAS E GAYS: QUESTÕES DE IDENTIDADE E ESTILO DISCUTIDAS EM ENTREVISTA DIRIGIDA
}

\author{
LINGUISTIC USES OF A GROUP OF LESBIANS AND GAYS: \\ ISSUES OF IDENTITY AND STYLE DISCUSSED IN A DIRECTED INTERVIEW
}

\author{
Ana Beatriz Oliveira Ribeiro | Lattes | anabeatrizopribeiro@gmail.com \\ Universidade Federal de Santa Catarina
}

Resumo: Este artigo busca investigar as percepções dos sujeitos de pesquisa acerca da(s) possível(is) identidade(s) lésbica(s) e gay(s), da fala como marcador dessa(s) identidade(s), e quais seriam os usos linguísticos associados a lésbicas/gays. O corpus constitui-se de quatro entrevistas realizadas em duplas com total de oito sujeitos (quatro mulheres autodeclaradas lésbicas e quatro homens autodeclarados gays). Para geração e análise desses usos, propõem-se um instrumental metodológico para o corpus de análise, considerando: interação, intimidade e informalidade. Estudos variacionistas de terceira onda (ECKERT, 2012, 2016) instauram-se na pós-modernidade - marcada pela fluidez dos sujeitos (RAMPTON, 2006) - e apresentam um redimensionamento, pois a) o significado social das variáveis é priorizado, sujeitos e suas práticas discursivas são o locus de análise; b) inverte-se a perspectiva da variação refletindo o lugar social para variação como recurso constitutivo de significado social; c) metodologias emergem das práticas estilísticas em que os sujeitos se envolvem. Assim, as metodologias não devem ser tomadas como fixas e não devem ser apenas replicadas sem considerar a multiplicidade dos sujeitos e das singularidades das pesquisas. Observou-se: i) os sujeitos de pesquisa acreditam que não há apenas uma identidade relacionada a lésbicas/gays; ii) a maioria apontou que se sentem confortáveis para demonstrar sua(s) identidade(s) com sujeitos LGBT ou pessoas íntimas e em lugares conhecidos; iii) todos consideram que a fala pode funcionar como um marcador de estilo e identidade(s) lésbica(s)/gay(s); iv) todos os sujeitos concordam que existem usos linguísticos característicos de lésbicas/gays.

Palavras-chave: Usos linguísticos de lésbicas e gays. Estilo. Identidade. Entrevista Dirigida. 
Abstract: This article seeks to investigate subjects' perceptions about the possible lesbian's and gay's identity on speech as a marker of these identity and, even if there are, what are the linguistic uses associated with lesbians/gays. The corpus consists of four interviews conducted in pairs with a total of eight subjects (four self-declared lesbian and four self-declared gay). To generate and analyze these uses, a methodological tool to analyze the corpus is proposed, considering interaction, intimacy and informality. Variationist third wave studies (ECKERT, 2012, 2016) establish themselves in post-modernity - marked by the fluidity of the subjects (RAMPTON, 2006) - and present a redimensioning, since a) the social variables are prioritized, subjects and their discursive practices are the locus of analysis; $b$ ) the variation perspective is reversed, reflecting the social place, for variation as a constitutive resource of social significance; and c) methodologies emerge from the stylistic practices in which the subjects are involved. Thus, methodologies should not be taken for granted and should not be replicated without considering the subjects multiplicity and the research singularities. It was observed that i) the subjects believe that there is not only an identity related to lesbians/gays; ii) the majority of them pointed out that they feel comfortable to demonstrate their identity with LGBT subjects or close people and in friendly places; iii) everyone considers that speech can act as a marker of lesbian/gay style and identity; and iv) all subjects agree that there are linguistic characteristic uses of lesbians/gays.

Keywords: Linguistic uses of lesbians and gays. Style. Identity. Directed interview.

\section{INTRODUÇÃO}

O Brasil é comumente associado à sua diversidade social compartilhada e vivenciada de diversas maneiras por seus cidadãos. Exemplos podem ser observados nas diferenças culturais, religiosas e relacionadas à sexualidade que, frequentemente, são estímulos que propiciam preconceito. Lamentavelmente, parte dos brasileiros ainda trata a(s) diferença(s) como algo nocivo, reproduzindo a discriminação e a intolerância.

Os ataques negativos à orientação sexual, expressados de modo verbal ou não, ainda ocorrem regularmente no contexto brasileiro ${ }^{1}$. Mesmo que o assunto tenha atualmente mais espaço nas mídias, a facilidade de expressão proporcionada pela internet é terreno fértil para usuários manifestarem opiniões discriminatórias sobre a comunidade LGBT. Ademais, as eleições do ano de 2018 e os discursos preconceituosos expressados no processo eleitoral legitimaram atitudes dessa natureza.

\footnotetext{
${ }^{1}$ O Brasil é o país que mais mata LGBTs: https://www12.senado.leg.br/radio/1/noticia/brasil-e-o-paisque-mais-mata-homossexuais-no-mundo. Acesso em: 30 out. 2018.
} 
Entretanto, debates envolvendo a comunidade LGBT intensificaram-se no Brasil, através da televisão e dos jornais ou através de discussões em ambientes que propiciam tal diálogo. Um acontecimento recente que elucida o aumento nessas discussões foi uma questão na prova de Linguagens do Exame Nacional do Ensino Médio (ENEM) de 2018. A questão tratava da linguagem usada por gays/travestis, chamada pajubá, e foi notícia em diversos sites ${ }^{2}$.

Este artigo $^{3}$ procura abordar algumas dessas discussões sobre sujeitos e comunidade LGBT, visando levantar e discutir questões envolvendo identidade e estilo. Para isso, esta pesquisa alinha-se com os estudos de terceira onda da Sociolinguística variacionista. Para propiciar essa discussão, foram realizadas entrevistas com mulheres autodeclaradas lésbicas e homens autodeclarados gays, visando captar as percepções dos sujeitos de pesquisa acerca da(s) possível(is) identidade(s) lésbica(s)/gay(s) e também acerca da fala como marcador dessa(s) identidade(s).

$\mathrm{O}$ artigo está estruturado em seis seções, sendo a primeira de introdução, em que se contextualiza brevemente a pesquisa. A segunda seção é reservada para a discussão sobre variação linguística, significado social, estilo e identidade. Já a terceira seção é destinada à discussão sobre o campo conceitual de gênero e sexualidade. A quarta seção é reservada aos encaminhamentos metodológicos adotados para a geração dos dados do trabalho. A quinta seção é constituída da análise dos dados da pesquisa. Por fim, a sexta seção é destinada para as considerações finais acerca do estudo.

\section{VARIAÇÃO LINGUÍSTICA, SIGNIFICADOSOCIAL, ESTILO EIDENTIDADE}

Os estudos na área da Sociolinguística variacionista (doravante SV) foram iniciados principalmente por Labov (1966) e pretendiam correlacionar usos linguísticos variáveis em comunidades de fala a condicionadores extralinguísticos. $\mathrm{O}$ foco social de análise era em macrocategorias (classe social, sexo/gênero e faixa etária), pressupondo que era possível estratificar os falantes dentro dessas categorias sociais previamente estabelecidas e estudar fenômenos de variação linguística correlacionados a essas categorias. Com o avanço dos estudos na área, outros pesquisadores deram diferentes tratamentos a seus trabalhos, diversificando o locus da pesquisa (comunidades de fala, redes sociais, comuni-

\footnotetext{
2 Ver: https://gauchazh.clicrbs.com.br/educacao-e-emprego/noticia/2018/11/enem-2018-conheca-a-origemdo-pajuba-dialeto-de-gays-e-travestis-citado-no-exame-cjo4maix90ben01pih135nzhn.html. Acesso em: 5 nov. 2018. A polêmica aconteceu porque muitas pessoas acharam que a questão deveria tratar de temas mais “profundos/culturais”. O presidente Jair Bolsonaro chegou a dizer que no próximo ano fiscalizará o conteúdo da prova.

3 Este artigo é resultado das discussões apresentadas na dissertação de mestrado da autora, intitulada "Usos linguísticos de lésbicas e de gays: questões de identidade e estilo” (2020).
} 
dades de prática), o foco no significado social (vinculado a macrocategorias, a significado local, a significado construído no grupo social) e a extensão da população investigada (foco na comunidade ou no(s) indivíduo(s)).

Essas diferentes abordagens levaram Eckert $(2005,2012)$ a sistematizar os estudos realizados na área, conhecidos como as três ondas da SV. É importante ressaltar que as "ondas” não são substitutivas nem sucessivas, mas configuram-se como modos distintos de estudar a variação, com práticas analíticas e metodológicas particulares, dependendo do foco de investigação de cada trabalho.

Os estudos de primeira onda - cujo marco inicial é o trabalho de Labov (2006 [1966]) - procuram compreender como e por que a variação acontece na comunidade de fala, a partir de pesquisas do tipo survey (quantitativas). Os pesquisadores gravavam entrevistas com falantes previamente estratificados, buscando encontrar suas falas mais espontâneas (vernáculo) e, então, investigar fenômenos linguísticos de uso variável (ECKERT, 2005, 2012). Correlações amplas entre variáveis linguísticas e categorias macrossociológicas são estabelecidas, resultando na identificação de padrões sociolinguísticos de uso.

Já a segunda onda desloca o foco para comunidades menores, e é comum o emprego de abordagens etnográficas ${ }^{4}$, investigando como as configurações locais e grupos sociais menores se encaixam nas macrocategorias sociais. Portanto, a escolha por determinado grupo social (e até pelo fenômeno linguístico a ser estudado) parte da experiência do pesquisador advinda in loco, em uma comunidade. Segundo Eckert (2005), os estudos etnográficos possibilitam entender melhor como os modos de falar estão imbricados no significado social.

O uso de determinadas variáveis linguísticas é constituinte da prática das comunidades, e, a partir disso, o significado social é adquirido, podendo ser compatível ou não com os construídos num âmbito mais amplo. Portanto, há uma forte relação entre usos linguísticos e identidade. Nesse sentido, ao significado estilístico é dado um tratamento diferente ao que é dado na primeira onda, pois entende-se que os indivíduos fazem uso de certas variantes para demonstrar uma variedade de afiliações, características, posturas e ideais (ECKERT, 2005).

A terceira onda de estudos da SV distancia-se das categorias estáticas (faixa etária, sexo/gênero e classe social), pois o indivíduo torna-se o foco e é visto como reflexo das

\footnotetext{
${ }^{4}$ Comumente utilizada por antropólogos, pesquisadores de diversas áreas têm usado a etnografia para estudar e entender modos de vida de sujeitos numa determinada cultura. $\mathrm{O}$ intuito é, portanto, compreender a visão de mundo, as atitudes, os significados e as experiências de um grupo social (ROSA; LUCENA; CROSSETI, 2003).
} 
identidades sociais, ou seja, o sujeito passa a ocupar, cada vez mais, um papel de agente nas pesquisas. Nessa onda, os significados sociais e estilísticos ocupam um espaço central, pois a variação é parte de um sistema social semiótico, em que não só a língua é considerada, mas toda a bagagem que o sujeito possui a partir de sua vivência em sociedade (ECKERT, 2012, 2016).

Ao passo que se considera que o sujeito experiencia diversas situações em sua vida, as categorias não teriam como ser estáticas e fixas, já que o indivíduo se modifica e se reorganiza constantemente, a depender dos contextos sociais, interlocutores etc. e, então, seu uso da língua é marcado por essa fluidez tanto social quanto estilística. Nesse sentido

[...] o significado da variação reside no seu papel na construção de estilos, e estudar o papel da variação na prática estilística envolve não simplesmente colocar variáveis em estilos, mas em entender esse posicionamento como parte integrante da construção do significado social ${ }^{5}$ (ECKERT, 2005, p. 24). ${ }^{6}$

Dessa forma, o olhar para variação na terceira onda extrapola o uso linguístico, visto que

[a] variação constitui um sistema semiótico social capaz de expressar toda a gama de questões sociais de uma comunidade. E como essas questões mudam continuamente, as variáveis não podem ser marcadores consensuais de significados fixos; pelo contrário, sua propriedade central deve ser a mutabilidade indexical (ECKERT, 2012, p. 84) 7 .

A presente pesquisa alinha-se com os estudos de terceira onda, pois procura-se relacionar a percepção dos sujeitos de pesquisa sobre identidade e usos linguísticos característicos de lésbicas/gays com os significados sociais, estilísticos e identitários que perpassam esses usos. Nesse sentido, os significados sociais e estilísticos da variação assumem características relativamente distintas em cada onda de estudos. Porém, com as identidades dos sujeitos cada vez mais fluidas e dinâmicas (RAMPTON, 2006), é difícil pensar nos usos da língua correlacionados apenas a macrocategorias, pois pode-se perder uma gama enorme de possibilidades que existem nas microcategorias, nos sujeitos situados

\footnotetext{
$s$ “ [... ] the meaning of variation lies in its role in the construction of styles, and studying the role of variation in stylistic practice involves not simply placing variables in styles, but in understanding this placement as an integral part of the construction of social meaning."

${ }^{6}$ Esta e todas as traduções ao longo do texto são de minha responsabilidade. Os excertos originais são apresentados em notas de rodapé.

7 "Variation constitutes a social semiotic system capable of expressing the full range of a community's social concerns. And as these concerns continually change, variables cannot be consensual markers of fixed meanings; on the contrary, their central property must be indexical mutability."
} 
política, histórica e socialmente. Neste artigo, atenta-se a concepções que compreendem estilo como indissociável do significado social, podendo ser observado tanto no indivíduo quanto num grupo, marcando identidade.

Nessa ótica, Eckert (2005, p. 24) assinala que "estilo (assim como a língua) não é uma coisa, mas uma prática. É a atividade em que as pessoas criam significado social. Nem

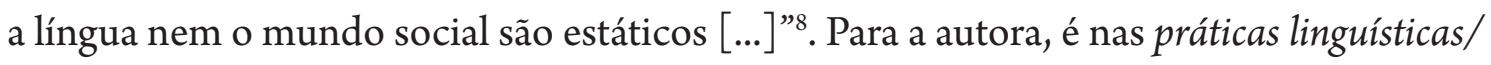
estilísticas que os sujeitos são (in)conscientemente agentes de suas próprias produções e o estilo se conecta fortemente com a ideologia. Nesse sentido, Eckert (2008) entende que a ideologia é central na prática estilística, pois cada movimento estilístico deriva de uma interpretação do mundo social e dos significados dos elementos desse mundo.

Para Irvine (2001, p. 42), estilo é “[...] um fenômeno verdadeiramente sociolinguístico, uma organização de distintividade que opera num plano linguístico”" Portanto, conforme os sujeitos vão desempenhando diferentes estilos, eles também vão projetando diferentes identidades/personas. Dessa forma,

[n]a sociolinguística variacionista de terceira onda, identidades são consideradas como sendo construídas e reconstruídas; elas são dinâmicas e mutáveis. Língua e identidade não podem ser separadas ou correlacionadas; elas são co-constitutivas (DRUMMOND; SCHLEEF, 2016, p. 53, grifo nosso) ${ }^{10}$.

Nessa perspectiva, é preciso entender como os sujeitos usam ou performam estilos sociais para diferentes propósitos simbólicos, e esses estilos funcionam como um recurso para os sujeitos desempenharem diversos significados pessoais e interpessoais (COUPLAND, 2007). Portanto, além da prática estilística relacionada ao uso da língua, é interessante investigar outros sistemas estilísticos desempenhados pelos sujeitos, como roupas, acessórios etc., e como esses dois planos estilísticos podem dialogar entre si.

Seguindo essa lógica, Kiesling (2013, p. 450, grifo no original) entende que “[...] $a$ identidade é como os indivíduos se definem, criam, ou pensam sobre si em termos de sua relação com outros indivíduos e grupos, sejam eles reais ou imaginários"11. Ou seja, é a partir da

\footnotetext{
8 "And style (like language) is not a thing but a practice. It is the activity in which people create social meaning. Neither language nor the social world is static [...]."

9 "[...] style as a truly sociolinguistic phenomenon, an organization of distinctiveness that operates on a linguistic plane."

10 "In TWVS (third-wave variationist sociolinguistic), identities are regarded as being constructed and reconstructed; they are dynamic and changeable. Language and identity cannot be separated or correlated; they are co-constitutive."

${ }_{11}$ "[...] identity is how individuals define, create, or think of themselves in terms of their relationships with other individuals and groups, whether these others are real or imagined."
} 
relação consigo mesmo, com outros sujeitos e também nas vivências em grupos sociais que a identidade dos sujeitos se (re)constrói e se (re)modifica, sejam essas relações reais ou imaginadas.

É a partir da variação que a(s) identidade(s) dos sujeitos é indexicalizada e, assim, são expressas suas visões de mundo. Segundo Joseph (2016), “cada um de nós performa um repertório de identidades que estão mudando constantemente e que negociamos e renegociamos de acordo com as circunstâncias (JOSEPH, 2016, p. 24)”. Belsey (1980, p. 132) já sugeria que os indivíduos devem ser vistos como "não fixados, insatisfeitos, não uma unidade, não autônoma, mas um processo, perpetuamente em construção, perpetuamente contraditório, perpetuamente aberto à mudança” ${ }^{12}$.

Nesse sentido, em vez de olharmos para comunidades de fala ( $1^{\text {a }}$ onda), parece mais interessante perceber como usos linguísticos funcionam dentro das comunidades de práticas (CP), que se referem a "um conjunto de pessoas agregadas em razão do engajamento mútuo em um empreendimento comum (ECKERT; MCCONNELL-GINET, 2010 [1992], p. 102)”. Isto é, os participantes de uma CP compartilham interpretações sobre outras comunidades, suas práticas em relação àquelas comunidades e o desenvolvimento de um estilo que perpassa essas interpretações (ECKERT, 2006). O propósito de estudar CPs é relacionar as formas de falar dos sujeitos com as maneiras como eles participam no mundo social, ou seja, investigar de que forma o significado social é incorporado na linguagem.

No interior das comunidade(s) de prática $(s)^{13}$, usos linguísticos podem apontar significados sociais e, assim, uma relação mais estreita entre língua e identidade pode ser estabelecida. Os estilos individuais de cada sujeito funcionam como marcas de identidades sociais e ocupam lugar central no estudo da variação linguística.

Dois requisitos são necessários para a composição efetiva de uma CP: experiência compartilhada ao longo do tempo e um compromisso de compreensão compartilhada (ECKERT, 2006, p. 683 $)^{14}$. Portanto, é preciso que sujeitos mantenham relações e experiências compartilhadas por algum período de tempo e que também tenham compreensões em comum, como visões de mundo, valores etc.

A constituição de uma CP também é ferramenta crucial para a (re)construção da identidade de seus participantes, o que também influencia seus repertórios linguísticos:

\footnotetext{
12 "unfixed, unsatisfied, not a unity, not autonomous, but a process, perpetually in construction, perpetually contradictory, perpetually open to change."

${ }^{13}$ Considera-se apropriado usar o termo no plural, visto que os sujeitos transitam por diversas CPs durante suas vidas.

14 " $[\ldots]$ shared experience over time and a commitment to shared understanding."
} 
Uma comunidade de prática, que é central para a maior parte da construção da identidade de seus participantes, é um importante locus para o estabelecimento da história conjunta, promovendo a construção complexa de estilos linguísticos (ECKERT, 2006, p. 684) ${ }^{15}$.

À medida que os sujeitos participam de diversas CPs durante suas vidas, é natural que, no interior delas, eles (re)modifiquem e (re)construam suas identidades continuamente. E isso reverbera em suas produções linguísticas e estilísticas, constantemente atravessadas por suas experiências. Dessa forma, estudar comunidades de práticas possibilita ao pesquisador um trabalho de caráter etnográfico, possibilitando entender e perceber as nuances que perpassam as experiências de seus participantes, visto que "[o] construto 'comunidade de prática' é uma maneira de localizar o uso da língua etnograficamente, de modo a criar um vínculo responsável entre a prática local e a associação em categorias extralocais e amplas" (ECKERT, 2006, p. 684) ${ }^{16}$.

No presente trabalho, entende-se que os sujeitos de pesquisa compõem uma comunidade de prática não prototípica, pois todos se conhecem, já transitaram pelos mesmos espaços e compartilham algumas visões de mundo e também modos de falar.

\section{GÊNERO E SEXUALIDADE}

Os estudos sobre gênero e sexualidade começaram a ser abordados pelas Ciências Humanas a partir das produções científicas decorrentes dos movimentos feministas no final do século XIX. O feminismo contemporâneo provém das diversas correntes feministas construídas ao longo do tempo. Nesse cenário, as contribuições da filósofa Judith Butler foram importantes, pois a autora procurou desconstruir o conceito de gênero no qual boa parte da teoria feminista se baseava. Dessa forma, Butler contribuiu significativamente para os estudos feministas e para as pesquisas de gênero/sexualidade, pois trouxe para a discussão os conceitos de performance e performatividade. Inspirada pelo trabalho de Austin (1962), Butler (2003 [1990]) propõe a ideia de gênero como algo performativo, oferecendo uma perspectiva para pensar para além dos conceitos canônicos que constituem binarismos como sexo e gênero, corpo e mente.

Segundo Butler (2003 [1990]), as performances de gênero ou sexuais não podem ser vistas como um prolongamento, uma continuação de um corpo já dado pela biologia (fêmea/macho). Em resumo, Borba (2014) aponta que

\footnotetext{
15 "A community of practice that is central to many of its participants' identity construction is an important locus for the setting down of joint history, allowing for the complex construction of linguistic styles."

16 "The construct 'community of practice' is a way of locating language use ethnographically so as to create an accountable link between local practice and membership in extralocal and broad categories.”
} 
performatividade não é um jogo livre nem uma autoapresentação teatral; não pode também ser igualada à performance. Além disso, a regulação não é necessariamente aquilo que coloca um limite à performatividade; a regulação é, ao contrário, aquilo que impele e sustenta a performatividade (BORBA, 2014, p. 449 apud BUTLER, 1993, p. 93).

Isso posto, entende-se que Butler compreende gênero e sexualidade como constituídos materialmente através de atos performativos, ou seja, atos de linguagem que não descrevem, mas constituem os sujeitos dentro de campos discursivos. Isso dialoga com a concepção de sexualidade defendida por Foucault:

A sexualidade é o nome que pode se dar a um dispositivo histórico: não à realidade subterrânea que se apreende com dificuldade, mas à grande rede da superfície em que a estimulação dos corpos, a intensificação dos prazeres, a incitação ao discurso, a formação dos conhecimentos, o reforço dos controles e das resistências, encadeiam-se uns aos outros [...] (FOUCAULT, 1988 [1999], p. 100).

A sexualidade é, portanto, algo construído socialmente e não dada a priori, já imbricada nos sujeitos no momento do nascimento. Pelo contrário, cada sujeito, inserido em dado contexto e sociedade, constrói sua sexualidade conforme o passar do tempo e de suas experiências. É nesse processo dinâmico que identidades, seja de gênero ou sexual, são construídas, desestabilizando, assim, o pensamento predominante do padrão heteronormativo.

A construção da identidade de sujeitos LGBT perpassa essas questões, ao passo que são esperadas determinadas performances (condutas) desses indivíduos. Por exemplo, em linhas gerais, de uma mulher é esperada a feminilidade, e de um homem a masculinidade. No imaginário popular, lésbicas são associadas à masculinidade e algo parecido acontece com gays, que frequentemente são associados à feminilidade. Porém, mesmo com essas performances socialmente esperadas, nem todas lésbicas/gays performam essa identidade encontrada no senso comum.

É importante destacar, neste momento, as diferenciações entre sexo, gênero e orientação sexual. Segundo Lanz (2014), o termo sexo está relacionado unicamente com a biologia, com o órgão genital (macho, fêmea, intersexuado ou nulo). O termo gênero está fortemente relacionado à construção social, coincidindo com as ideias de Butler e Foucault. O termo orientação sexual diz respeito ao desejo afetivo do indivíduo. A orientação não está relacionada somente com o sexo, nem com identidade de gênero, mas tem 
relação unicamente com a atração física e emocional entre pessoas (homossexual ou heterossexual).

Muitas abordagens nas Ciências Humanas estão voltadas para questões envolvendo o sujeito e as relações interpessoais que experienciam. Segundo Goffman (1959), a maioria de nossas ações e condutas são reguladas durante um processo de representação do Eu na relação com o Outro. É para desempenhar determinados papéis sociais que conduzimos diferentes performances durante nossa vida cotidiana.

Cada papel representado por sujeitos, LGBT ou não, revela uma nova máscara social. Esse processo performático faz com que o sujeito seja capaz de transformar-se, de desconstruir-se e remontar-se a cada nova peça desse "quebra-cabeça corporificado", e, assim, os sujeitos constroem diferentes personas ${ }^{17}$ para essa representação. Stuart Hall (2006) entende que somos diferentes continuadamente porque assumimos, durante nossa vida cotidiana, diversos papéis sociais; logo, nossas identidades não estão fundidas em apenas um "eu”, mas em vários.

Neste trabalho, portanto, entende-se gênero como construção de papel social e isso envolve como os sujeitos se relacionam com o mundo. Esse encontro com o mundo atravessa e constitui também a construção da identidade. Partindo de conceituações diferenciadas, porém complementares, entende-se que a conceituação de gênero trata de uma construção social, política, histórica, cultural e religiosa, que atravessa e perpassa os sujeitos e suas práticas repetidamente.

\section{ENCAMINHAMENTOS METODOLÓGICOS}

Nesta seção, explicita-se como se deu a geração ${ }^{18}$ dos dados para constituição do corpus de análise, detalha-se o perfil do grupo e os sujeitos de pesquisa e explica-se o tratamento dado às entrevistas, assim como às etapas de transcrição e análise.

Nos estudos variacionistas de terceira onda, entende-se que as identidades dos sujeitos são múltiplas e fragmentadas, e isso deve ser considerado na escolha dos procedimentos metodológicos. Consequentemente, metodologias devem ser construídas a partir das práticas estilísticas dos sujeitos. Este estudo conta com quatro entrevistas, totalizando oito sujeitos de pesquisa (quatro homens autodeclarados gays e quatro mulheres autodeclaradas lésbicas).

\footnotetext{
17 Segundo Jung (1975), persona é uma máscara que o sujeito assume frente as demandas e convenções socialmente estabelecidas e ela representa uma parcela significativa do comportamento do sujeito enquanto entidade coletiva.

${ }^{18}$ Preferiu-se esse termo, pois entende-se que as entrevistas e o intuito da pesquisa preza por uma postura mais agentiva dos sujeitos.
} 
Visando propiciar o surgimento de usos linguísticos de lésbicas/gays e também reflexões sobre tais usos e as identidades dos sujeitos, propôs-se um instrumental de geração de dados para constituir o corpus de análise. Esse modelo consiste na concatenação de três aspectos para a realização das entrevistas: interação, intimidade e informalidade. Quanto à interação, as entrevistas foram realizadas em duplas (dois homens gays e duas mulheres lésbicas), objetivando conforto para os participantes na conversa. Quanto à intimidade, as duplas foram dispostas nos graus de maior e menor intimidade ${ }^{19}$. Relativamente à informalidade, o roteiro de perguntas foi elaborado para tornar a conversa mais informal. As seguintes etapas foram seguidas para realização do trabalho: 1) Elaboração da ficha social; 2) Elaboração do roteiro de entrevista e 3) Recrutamento e pareamento dos sujeitos.

A partir da constituição do corpus, realizou-se a transcrição e a análise de quatro entrevistas das duplas com intimidade: duas com mulheres lésbicas (Ametista e Adore/ Gezebel e Catarina) e duas com homens gays (Júlio e Pedro/Scorpio e Dino), totalizando oito sujeitos de pesquisa.

É interessante pontuar que todos os sujeitos de pesquisa estudam ou estudaram na Universidade Federal do Rio Grande (FURG) e, ainda, todos cursaram o mesmo curso: Letras, apenas diferenciando à ênfase da língua estrangeira. Além disso, todos conviveram por algum tempo na universidade, dentro do Instituto de Letras e Artes (ILA), em disciplinas do curso e em eventos da universidade.

Scorpio e Dino conheceram-se na universidade e começaram a namorar durante o curso de Letras. Adore foi estagiária de Português em uma turma de Ametista no Instituto Federal de Rio Grande (IFRS). Júlio, Scorpio, Dino e Catarina formaram-se no curso de Letras juntos, em 2017. Gezebel e Adore também se formaram juntas no curso de Letras em 2018. Júlio trabalhava como atendente em um cursinho pré-vestibular coordenado por Pedro.

Pode-se dizer que os laços que unem os oito sujeitos de pesquisa, em suma, são quatro: 1) orientação sexual; 2) residir na cidade de Rio Grande; 3 ) frequentar a FURG e 4) ser da área de Letras. Assim, considera-se que eles formam uma comunidade de prática não prototípica. ${ }^{20}$

As entrevistas foram transcritas a partir da oitiva dos áudios, e o Microsoft Word foi usado para o processo de digitação. A análise deu-se por um olhar qualitativo,

\footnotetext{
${ }^{19}$ Entende-se intimidade com base nos seguintes critérios: mais íntimo - amigos, colegas de faculdade/ trabalho; menos íntimo - conhecidos, com pouco contato ou totalmente desconhecidos.

${ }^{20}$ Entende-se que os sujeitos de pesquisa formam uma CP não prototípica, pois embora todos tenham cursado o curso de Letras, e a maioria tenha frequentado a Universidade durante o mesmo período, um dos sujeitos, Pedro, não frequentou a Universidade com os outros sujeitos.
} 
buscando captar e problematizar a percepção dos sujeitos de pesquisa acerca dos usos linguísticos característicos de lésbicas/gays e sua relação com identidade. Parte-se do imaginário popular acerca de usos linguísticos característicos de lésbicas/gays, para, então, problematizar a percepção dos sujeitos de pesquisa acerca desses usos.

\section{O OLHAR PARA OS DADOS}

Nesta seção, discutem-se as percepções dos sujeitos de pesquisa acerca de temas propostos nas entrevistas ${ }^{21}$. O capítulo está dividido em duas grandes seções: percepções sobre identidade e percepções sobre usos linguísticos, e cada uma delas está subdividida em subseções menores.

Faz-se pertinente reforçar que as percepções fornecidas pelos sujeitos de pesquisa podem recair em estereótipos, visto que nenhum indivíduo, pertencente a um grupo minoritário ou não, está liberto de corroborar certos estigmas sociais. Nessa lógica, Eckert confirma que " $[\mathrm{n}]$ ós distinguimos as pessoas com base em nossa percepção de suas qualidades, crenças, atitudes e ações. Nós as categorizamos com base nos agregados percebidos dessas qualidades, crenças, atitudes e ações (ECKERT, 2016, p. 6)”22.

É significativo frisar que o momento político era propício para posicionamentos críticos, pois o ano de 2018 foi marcado por acontecimentos político-ideológicos de ordem conservadora. Alguns entrevistados relatam medo e apreensão com o cenário político brasileiro e com os discursos preconceituosos que vinham acontecendo.

\subsection{Percepções sobre identidade}

Nesta seção, discutem-se as percepções das quatro duplas envolvendo o tema "identidade”. Dessa forma, a seção está subdividida em quatro tópicos: existência de uma identidade lésbica/gay; tipos de lésbicas/gays; ambientes e pessoas que se sentem confortáveis para mostrar identidades; e fala como marcador de identidades lésbica/gay.

\subsubsection{Existência de uma identidade lésbica/gay}

Ametista e Adore entendem as identidades dos sujeitos como plurais, e é delicado tentar encaixá-los em categorias socialmente pré-concebidas. Segundo elas, não se deve limitar essas identidades, mesmo que diversas generalizações existam. Para elas, existe

\footnotetext{
${ }^{21}$ Os trechos completos das entrevistas encontram-se na dissertação de mestrado da autora, intitulada "Usos linguísticos de lésbicas e de gays: questões de identidade e estilo" (2020).

22 "We distinguish people based on our perception of their qualities, beliefs, attitudes, and actions. We categorize them on the basis of perceived aggregates of these qualities, beliefs, attitudes, and actions $[\ldots] . "$
} 
uma pluralidade de mulheres, "mulheridaDES", o que gera uma pluralidade de "lesbianiedaDES”. Ametista relata que "não existe uma identidade para nada" e Adore acrescenta que tentam forçar sujeitos LGBT a terem uma identidade, mas isso não existe.

A percepção da dupla está em sintonia com as concepções pós-modernas sobre identidade. Nesse panorama, as identidades dos sujeitos são tidas "como sendo construídas e reconstruídas; elas são dinâmicas e mutáveis" (DRUMMOND; SCHLEEF, 2016, p. 53 , grifo nosso $)^{23}$. Os relatos delas também apontam para o que diz Joseph (2016): "cada um de nós performa um repertório de identidades que estão mudando constantemente, e que negociamos e renegociamos de acordo com as circunstâncias (p. 24)”24.

Júlio e Pedro também entendem as identidades como plurais. Eles discorrem sobre como as identidades são vistas no imaginário popular, como estereótipos, em que homens gays se aproximariam de mulheres e mulheres lésbicas se aproximariam de homens.

Júlio acrescenta que, entre os homens gays, existem vários tipos, várias classificações, que são explicadas por ele mesmo no decorrer da entrevista. Ademais, Pedro diz considerar o tópico identidade bastante complexo e que acha que esse assunto ainda está "em construção".

Podemos relacionar suas percepções com a concepção pós-moderna de identidade, que entende que os sujeitos não podem ser reduzidos a uma única "categoria”, pois são formados por diversas identidades intercambiáveis e fluidas.

Dino e Scorpio também compreendem identidade como plural. Dino acredita talvez existir um conjunto de traços que identifiquem os sujeitos, mas não acha que existe um único jeito de ser. Ele ainda sinaliza que problemas enfrentados por sujeitos LGBTs com suas famílias podem marcar a identidade deles de alguma maneira.

Scorpio, por sua vez, discorre sobre como a comunidade LGBT criou determinadas maneiras de ser, resultando em "muitas construções" do que é ser LGBT. Ele contrapõe a ideia de pluralidade à tentativa de uma certa padronização que é imposta, ao dizer que, até mesmo no universo gay, existe "um certo padrão" em que os sujeitos precisariam encaixar-se.

O pensamento da dupla leva ao que dizem Drummond e Schleef (2016, p. 53-54): "a identidade não está localizada com o indivíduo; identidades são construídas intersubjetivamente através de uma variedade de relações”25.

\footnotetext{
${ }^{23}$ Cf. nota de rodapé 15 .

24 "Each of us performs a repertoire of identities that are constantly shifting, and that we negotiate and renegotiate according to the circumstances."

25 "Identity is not located with the individual; identities are constructed inter-subjectively through a variety of relations."
} 
Gezebel e Catarina discutem sobre os estereótipos envolvendo lésbicas/gays. Sobre lésbicas, apontam: cabelo curto, uso de óculos, tatuagens, uso de roupas mais masculinas, uso de camisa xadrez, uso de anel de coquinho etc. Quanto a gays, elas apontam: bicha poc, como homens afeminados e que gritam, usam calças justas etc.

Gezebel adiciona que existem os estilos e que identificamos sujeitos LGBT a partir deles. Ela acrescenta que existe o "gaydar", que seria um radar para identificar sujeitos LGBT. Essa ideia dos estilos levantada por Gezebel pode ser associada ao que diz Eckert (2016, p. 6): "[n]ós distinguimos as pessoas com base em nossa percepção de suas qualidades, crenças, atitudes e ações. Nós as categorizamos com base nos agregados percebidos dessas qualidades, crenças, atitudes e ações" ${ }^{26}$.

Pode-se dizer que a dupla considera que, mesmo que existam estereótipos, as identidades são plurais e são manifestadas através dos estilos individuais dos sujeitos. Nessa lógica, Belsey (1980, p. 132) já apontava que os indivíduos devem ser vistos como "não fixados, insatisfeitos, não uma unidade, não autônoma, mas um processo, perpetuamente em construção, perpetuamente contraditório, perpetuamente aberto à mudança” ${ }^{27}$.

\subsubsection{Diferentes tipos de lésbicas/gays}

Ametista e Adore pontuam alguns tipos de lésbicas presentes no imaginário popular, como caminhão, femme e dyke. Ametista também aponta que a identidade das roupas é um fator que facilita a identificação de sujeitos LGBT.

Adore acrescenta acreditar que essas identificações estão tornando-se mais fluidas e, por isso, fica difícil colocar as pessoas em caixinhas fixas. Segundo ela, há momentos em que lésbicas estão performando um estilo mais caminhão e, em outros, um estilo mais feminino. Ametista concorda e relata que no verão ela usa saias (mais feminina) e no inverno ela é mais sapatão (mais masculina), ou seja, ela identifica-se nos dois extremos, e Adore diz identificar-se com o tipo mais feminino.

Os apontamentos da dupla levam ao que afirma Stuart Hall (2006), que entende que somos diferentes constantemente, pois assumimos, durante nossa vida cotidiana, diversos papéis sociais, e, portanto, nossas identidades não estão fundidas em apenas um "eu”, mas sim em vários.

Júlio e Pedro conversam sobre tipos que conhecem. Para gays, eles apontam: bear (gordinho/peludo), twink (magro, sem pelos e jovem), daddy (mais velho, forte, o papai). Já para lésbicas, pontuam: femininas, fanchonas, que se vestem parecidas com heterossexuais masculinos, também chamadas de caminhoneiras.

\footnotetext{
${ }^{26}$ Cf. nota de rodapé 22.
}

${ }^{27} \mathrm{Cf}$. nota de rodapé 19. 
A noção de estereótipo está estritamente ligada com a expectativa dos outros indivíduos e seus respectivos desempenhos em sociedade, em que determinadas condutas são previamente estabelecidas e regram, de certa forma, como os sujeitos devem ou não se comportar.

Pedro diz que talvez se identifique com o tipo ursa, já Júlio afirma não se identificar com nenhum dos tipos. É interessante perceber que, por mais que Júlio conheça as classificações, ele não se identifica com nenhum dos tipos citados, indicando como a identidade é realmente fluida, pois as caixas não o definem.

Scorpio e Dino discutem algumas classificações. Scorpio aponta tipos de lésbicas: lipstick (femininas), butch (masculinas) e sporty (academia). Sobre gays, ambos acreditam que as classificações são bastante associadas com sexo. Também pontuam o tipo bear (gordo/peludo) e lontra (magro, alto e peludo).

Scorpio diz identificar-se com o tipo bear, mas o que é interessante é compreender como ele chega nessa classificação. Segundo ele, faz isso para ser aceito e não porque deseja encaixotar-se/classificar-se. Nesse sentido, o rótulo lhe é imposto, sob pena de não encontrar nenhum interessado nele.

Gezebel e Catarina focam na classificação de lésbicas e mencionam alguns tipos: caminhoneira, lady, $M P B$, good vibes e 4:20, que é um termo referente à maconha ou ao usuário dela.

Catarina diz identificar-se com algumas coisas relacionadas a esses tipos, como gostar bastante de MPB. Gezebel brinca e diz gostar de camisa xadrez e levanta um ponto interessante, diz identificar-se num meio termo, entre as mais femininas e as mais masculinas, pois não se vê em nenhum dos extremos.

\subsubsection{Ambientes e pessoas que se sentem confortáveis para mostrar identidades}

Ametista e Adore discutem o tema e Ametista comenta que o atual momento brasileiro a deixa com bastante medo de mostrar sua(s) identidade(s). Porém, com família e amigos, ela sente-se bastante confortável.

Adore pontua que apenas se sente à vontade com a sua namorada e um grupo próximo de amigos, e que não é com qualquer conhecido que se sente confortável para mostrar sua(s) identidade(s). Ela também relata fugir da performance de identidade com sua família. No trabalho, Adore diz que tem tentado naturalizar sua orientação sexual, mas ainda não se sente totalmente confortável. Nesse sentido, Butler (1993) entende que repetidas performances desempenhadas pelos sujeitos geram condições para repensarem 
quais significados podem estar associados ao uso de seus corpos, e isso lhes permite criarem novas concepções sobre si mesmos.

Júlio e Pedro apontam não possuir problemas em mostrar sua(s) identidade(s) para pessoas. Júlio relata que seria mais reservado em certos lugares, como ônibus ou igreja, mas na presença de amigos costuma ser espontâneo.

O relato de Júlio leva à ideia de estilo como distintividade, pois Irvine (2001) entende que o estilo só se dá a partir do confronto e na presença do outro e também de outros estilos. Isso ocorre, pois Júlio menciona que só saberiam que ele é gay se ele estivesse com alguém, ou seja, em oposição à outra pessoa, com outro estilo.

Dino e Scorpio refletem sobre a pergunta e Dino conta que se sentia bastante confortável para mostrar sua(s) identidade(s) com amigos e na faculdade. Porém, com a atual situação brasileira, ele relata estar com medo de continuar expondo-se.

Scorpio relata que mudou alguns hábitos, por exemplo, ele não se sente mais à vontade em estar de cabelo solto dentro da sala de aula (ele tem o cabelo comprido), pois acredita ser mais aceitável estar de cabelo solto na rua.

Felix (2016, p. 74) discute sobre os estilos de fala e diz que "[os informantes] se mostram bastantes conscientes com relação ao seu ser e ao seu falar e afirmam moldar o seu comportamento e, consequentemente, sua fala dependendo da audiência a que se dirige”. Aparentemente, Scorpio e Dino, de certo modo, acomodam suas falas a depender do interlocutor e do contexto em que estão inseridos. A motivação para isso seria o medo de serem ridicularizados, caso revelassem suas identidades.

Catarina e Gezebel relatam que não se sentiriam confortáveis em ambientes heterossexuais. Catarina declara que se sente confortável para mostrar sua(s) identidade(s) em sua casa e em ambientes que sejam LGBT friendly ${ }^{28}$. Gezebel também diz sentir-se confortável na faculdade.

Nessa direção, os informantes de Felix (2016) "afirmam buscar um afastamento do seu estilo gay quando em contextos de trabalho ou em meio a homens heterossexuais, porém lançam mão desse estilo quando estão com seus amigos também gays”. A dupla converge com essa percepção e não se sente confortável para mostrar suas identidades em ambientes e pessoas desconhecidas.

\subsubsection{Fala como marcador de identidades lésbica/gay}

Ametista e Adore acreditam que a fala pode funcionar como marcador de identidades lésbica/gay. Adore não considera ser o único mecanismo disponível para essa

\footnotetext{
${ }^{28}$ Expressão em inglês para algo amigável. Nesse caso, lugares que aceitem sujeitos LGBT.
} 
marcação, mas considera que a fala seja um mecanismo importante. Ametista acrescenta existir um vocabulário mais específico da comunidade, que leva à identificação.

Mendes (2012) já pontuava que o imaginário popular parece associar determinados usos linguísticos à fala de sujeitos homossexuais e esses usos podem ser atravessados/ motivados por questões identitárias e de pertencimento ao universo LGBT.

Júlio e Pedro também acreditam que a fala pode funcionar como um marcador de identidades lésbica/gay. A dupla fornece exemplos como passiva/passiva nefasta e passivona. O relato da dupla leva ao que Lau (2017) discutia sobre alguns membros da comunidade: necessitando comunicar-se de forma mais velada, utilizam o "bichês".

Scorpio e Dino também apontam que a fala pode funcionar como um marcador de identidades lésbica/gay. Dino acrescenta que isso está presente no vocabulário e no modo de falar. Eles mencionam que a entonação parece ser diferente: fala mais alta e tom de voz agudo. Mendes (2012) já apontava que a entonação e o modo de falar são fatores que seus informantes associaram à fala de gays.

Gezebel e Catarina também concordam que a fala pode funcionar como um marcador de identidades lésbica/gay. Catarina, fazendo referência à questão do ENEM de $2018^{29}$ envolvendo o pajubá, menciona que existem gírias que seu avô não entenderia, como amapô (mulher) e aqué (dinheiro). Isso acontece porque a compreensão dos usos é viabilizada pela convivência com sujeitos LGBT.

Em suma, com relação à identidade, foco da seção 5.1, pode-se dizer que os sujeitos a entendem como plural e dinâmica e discordam da visão estereotipada sobre o assunto, o que coaduna com a concepção pós-moderna de identidade(s) fluida(s).

\subsection{Percepções sobre usos linguísticos}

Nesta seção, discutem-se as percepções das quatro duplas referentes a usos linguísticos. A seção está subdividida em quatro tópicos: usos linguísticos característicos do universo LGBT, fatores que podem propiciar esses usos, formas de referência a lésbicas/gays e apropriação e ressignificação dos usos por sujeitos heterossexuais.

\subsubsection{Usos linguísticos característicos do universo LGBT}

Ametista e Adore discutem o assunto e Adore aponta que percebe usos linguísticos como sapatão, lésbica e caminhoneira, mas não fora do contexto da comunidade LGBT. Já Ametista discorre sobre marcações de feminilidade através da fala e ela, por exemplo, usa bastante as gírias mano e saca, demonstrando baixa marcação da feminilidade.

${ }^{29}$ Cf. nota de rodapé 2 . 
É interessante o uso da expressão tá ligado. Valle (2014) já defendia que o uso de marcadores discursivos (MDs) pode marcar identidade. Na terceira onda, os usos linguísticos e seus significados também são fluidos e mutáveis. Por exemplo, Bentes e Mariano (2013) analisam MDs, especificamente o tá ligado, percebendo que o item funciona como indexicalizador de identidade dos manos e rappers, podendo funcionar como marca de masculinidade, o que combinaria com o uso de tá ligado apontado por Ametista, no nosso caso, como indexicalizador identitário ligado à baixa performance da feminilidade.

Júlio e Pedro fornecem exemplos de usos linguísticos do universo LGBT, como: mona, neca (pênis), aquendar (esconder o pênis), picumã (cabelo/peruca) e chuca (enema). Além disso, eles também discutem a restrição no entendimento de determinadas palavras e/ou expressões. Eles acentuam que sujeitos LGBT usam uma linguagem que é acessível para aqueles pertencentes à comunidade, mas de difícil compreensão por aqueles que não pertencem a ela.

A condição dessa restrição pode ser explicada se compreendermos que é através do contato e/ou pertencimento ao universo LGBT que a compreensão desses usos pode ser viabilizada. Esses usos linguísticos perpassam as identidades dos sujeitos LGBT a partir de um conjunto de práticas sociais e linguísticas.

Scorpio e Dino fornecem exemplos de usos do universo LGBT, como lacrou, maravilhosa, nhaí, bofe, boy, boy magia. Dino acrescenta adjetivos usados no feminino, como detonada e arregaçada. Isso remete à dissertação de Santana (2018) sobre o uso de adjetivos predicativos com gênero gramatical feminino por homens gays.

Gezebel e Catarina fornecem alguns exemplos de usos do universo LGBT, como $c y$ (uso antigo para ânus), chuca (enema), cunete (beijo grego), aqué (dinheiro), dar/fazer a elza (roubar), fazer a egípcia (agir com indiferença).

\subsubsection{Fatores que propiciam usos linguísticos característicos do universo LGBT}

Ametista e Adore debatem a questão e Ametista sugere que música e ambientes para lazer são fatores que podem propiciar usos linguísticos característicos do universo LGBT. Adore adiciona que o conforto que se sente é um fator que propicia os usos.

Júlio e Pedro têm a percepção de que o interlocutor é o fator que mais favorece usos linguísticos característicos de lésbicas/gays, porque, para eles, a compreensão dos usos será viabilizada primeiramente pelo interlocutor, sendo o contexto um segundo fator. Nesse sentido, Santana (2018, p. 38) indica que "o interlocutor desempenha papel imprescindível na escolha de estilos feita pelos falantes”. 
Scorpio e Dino discutem o assunto, e Dino revela que há uma associação entre estilo de fala e o lugar onde se fala. Então, para ele, o contexto é um fator importante que propicia usos linguísticos característicos do universo LGBT. Os dois relatam que fariam uso das palavras/expressões apenas com sujeitos LGBT.

Os apontamentos da dupla vão ao encontro do que diz Santana (2018, p. 71, grifo nosso), que os usos "são reservados para interação com interlocutores da própria comunidade e têm funções específicas de expressar brincadeira, informalidade e/ou intimidade”.

Gezebel e Catarina apontam que o contexto é fator que propicia usos linguísticos característicos do universo LGBT, pois não é em todo lugar que são usadas essas palavras/expressões. Depois, também pontuam que não se usa certos termos com quem não é LGBT, pois seriam incompreensíveis. Ou seja, também reconhecem que o interlocutor é outro fator que influencia no uso. Como aponta Barroso (2017, p. 92), "é preciso observar que não se pode falar sempre o que queremos sem observar o ambiente e nossos interlocutores". Ou seja, é preciso atentar-se para o lugar e com quem se fala, para empregar determinados usos linguísticos.

\subsubsection{Formas de referência a lésbicas/gays}

Ametista e Adore apontam que, entre amigas/os e pessoas próximas, usam bastante os termos sapatão, viado, bicha. Segundo Ametista, entre suas amigas lésbicas, usam a palavra sapatão como forma de afirmação.

É pertinente ressaltar que, aparentemente, há dois requisitos fundamentais que autorizam ou não o uso desses termos: pertencer à comunidade LGBT e ter intimidade/ proximidade com quem se fala. A noção de lugar de fala parece ser crucial para definir quem pode ou não usar palavras/expressões da comunidade LGBT, ou seja, "quem pode falar ou não, quais vozes são legitimadas e quais não são (RIBEIRO, 2017, p. 16-17)”.

Júlio e Pedro apontam a necessidade da intimidade para chamar/ser chamado de determinadas maneiras. Pedro diz usar bastante os termos bixona, passiva feroz/passiva nefasta para referir-se a gays e, para referir-se a lésbicas, relata usar sapatão/sapatão futurístico.

Pedro frisa a necessidade de intimidade para ser chamado por certos termos e que sujeitos heterossexuais não estão autorizados a utilizá-los. Júlio concorda, dizendo que “tudo precisa de intimidade”. Santana (2018) já apontou que a identidade gay é projetada, preferencialmente, na companhia de outros gays e, exclusivamente, quando esses interlocutores possuem proximidade e estão num ambiente descontraído. Através da lín- 
gua, sujeitos LGBT projetam suas personas e identidade(s), principalmente na companhia de outros sujeitos LGBT ou pessoas próximas.

Scorpio e Dino debatem a questão e Dino relata usar os termos gay e lésbica. Já Scorpio diz usar mais os termos do inglês, como butch. Ambos salientam que só gostam de ser chamados por esses termos por pessoas íntimas e, principalmente, pertencentes à comunidade LGBT, já que, segundo Dino, "quando o outro usa, outro de fora, tem outro peso". A dupla também conversa sobre a noção de lugar de fala, pois mencionam que apenas pessoas próximas ou pertencentes à comunidade LGBT estão autorizadas a usar determinados termos.

Gezebel e Catarina discutem o assunto e Catarina aponta usar os termos viado, bicha e sapatão, mas que acha que só lésbicas/gays podem usar tais termos. Isso leva ao entendimento de lugar de fala como sendo lugar de expressão de dado grupo social, em que os indivíduos se colocam enquanto sujeitos, ou seja, o lugar de fala de indivíduos LGBTs é onde eles têm a oportunidade de colocar-se como sujeitos, para seu grupo, sem medo de sofrer preconceito.

Sobre como são chamadas, Catarina menciona que sua família costuma chamá-la de sapatão, mas que não gosta quando pessoas que não têm intimidade a chamam assim, pois pode soar desrespeitoso. Já Gezebel relata não se recordar de pessoas usando o termo sapatão para referir-se a ela. Isso pode acontecer porque Gezebel não performa nenhum dos polos extremos da feminilidade e da masculinidade, pois transita em um meio termo.

\subsubsection{Apropriação dos usos linguísticos do universo LGBT por sujeitos heterossexuais}

Ametista e Adore parecem não gostar quando sujeitos heterossexuais utilizam usos linguísticos do universo LGBT. Adore acredita que os sujeitos heterossexuais devem pensar "só quero fazer parte dessa coisa legalzinha que vocês usam uns vocábulos", e que eles usam para encaixar-se na comunidade, mas não querem a "dor dessa comunidade". Além disso, Adore também considera haver certa apropriação da cultura LGBT por parte de sujeitos heterossexuais.

Sobre esses usos por sujeitos heterossexuais poderem impactar a identidade da comunidade LGBT, ambas acreditam apenas reforçar estereótipos existentes. Sobre esses usos poderem contribuir para diminuir a homofobia, Ametista acredita talvez impactar a identidade da comunidade LGBT apenas de forma velada e falsa, pois, para ela, sujeitos heterossexuais usam as expressões apenas "pro riso". 
Júlio e Pedro também desaprovam os usos linguísticos do universo LGBT por sujeitos heterossexuais. Júlio aponta que sujeitos heterossexuais fazem usos equivocados das expressões. Pedro concorda e acrescenta que além de usarem errado, não usam espontaneamente. Júlio ainda usa a expressão "no nosso dicionário", demonstrando que a linguagem pertence somente aos membros da comunidade LGBT.

Sobre esses usos por sujeitos heterossexuais poderem impactar a identidade da comunidade LGBT, Júlio acredita que para alguns talvez exista essa luta para não usarem, pois marca identidade. Sobre a reação deles ao verem um desconhecido usar essas expressões do universo LGBT, Pedro diz primeiramente estranhar e Júlio diz pensar: "sério que tás usando isso, não tens nada teu para usar?", e Pedro finaliza: “tens que tá roubando dos outros?", demonstrando, portanto, uma avaliação bastante negativa.

Barroso (2017, p. 43) já discutia que "os indivíduos fazem dessas marcas grupais uma forma de se autoafirmarem na sociedade". Desse modo, os sujeitos LGBT usam palavras e expressões diferentes, como um mecanismo para afirmar suas identidades.

Scorpio e Dino também desaprovam sujeitos heterossexuais empregando usos linguísticos do universo LGBT. Sobre esses usos poderem impactar a identidade da comunidade LGBT, Dino relata aspectos positivos e negativos. $\mathrm{O}$ aspecto positivo é que, se a maioria das pessoas fala, sujeitos LGBT não se sentiriam mal em usar as expressões da comunidade. $\mathrm{O}$ aspecto negativo é que, se heterossexuais usarem os termos que são da comunidade, as pessoas que se identificam com esse grupo perderiam traços de sua identidade. Scorpio concorda e adiciona que quando todos começam a usar, toda uma cultura pode ser perdida.

Sobre esses usos poderem contribuir para diminuir a homofobia, Scorpio não acredita acontecer isso e que pode, eventualmente, apagar a história da comunidade LGBT. Se antes a língua usada por LGBTs era um sistema de proteção, isso pode não mais acontecer. A língua é usada também para criar significados sociais, o que também perpassa a (re)construção das identidades. A língua usada por sujeitos LGBT é componente crucial na construção de sua(s) identidade(s), e usar essa língua parece ter um significado social bastante valioso para eles. Talvez por isso esses sujeitos se incomodam quando pessoas que não pertencem à comunidade usam as expressões que comumente eles usam.

Gezebel e Catarina demonstram reprovar quando sujeitos heterossexuais utilizam as expressões da comunidade LGBT. Catarina brinca que esse uso seria apropriação cultural e Gezebel relata achar engraçado quando usam. Gezebel diz não encontrar muitas pessoas usando as expressões, mas percebe muita demanda para saber seus significados, 
que são tão naturais para quem pertence à comunidade que se torna difícil explicar.

Sobre esses usos por sujeitos heterossexuais poderem impactar a identidade da comunidade LGBT, ambas não consideram haver algum impacto. Catarina diz que a linguagem para LGBTs é uma forma de identificação: "nos construímos como sujeitos através da linguagem”. Sobre esses usos poderem contribuir para diminuir a homofobia, ambas acreditam ser algo pequeno para causar impacto. Sobre a reação delas ao verem um desconhecido usando essas expressões, Gezebel relata que talvez achasse que seria um sujeito LGBT, mas então faria o "raio-x do estilo" (consideraria outros elementos simbólicos como vestimenta, jeitos etc.) para chegar a alguma conclusão.

Isto remete à concepção de estilo e dos múltiplos símbolos que compõem o estilo dos sujeitos, e a linguagem pode ter um papel fundamental nessa composição estilística. Irvine (2001, p. 23-24) discorre sobre os estilos de fala e diz que "[...] estilos de fala envolvem as maneiras pelas quais os falantes, agentes no espaço social (e sociolinguístico), negociam suas posições e objetivos num sistema de distinções e possibilidades"30.

Em suma, com relação aos usos linguísticos característicos de lésbicas/gays, foco da seção 5.2, pode-se dizer que os sujeitos consideram a existência desses usos, fornecem exemplos, mas apontam que esses usos são mais restritos à comunidade LGBT e, por isso, podem não ser compreendidos por quem não possui contato com a comunidade.

\section{CONSIDERAÇÕES FINAIS}

Este artigo teve por intuito principal agregar aos trabalhos que resistem e persistem na árdua tarefa de não se silenciar frente ao sexismo, à misoginia e à homofobia ainda tão arraigados em nossa cultura. Portanto, tentando desmistificar certos tópicos sobre lésbicas/gays, este trabalho procurou captar algumas percepções desses sujeitos sobre assuntos envolvendo suas vivências, como identidade e usos linguísticos.

Procurou-se investigar a percepção dos sujeitos de pesquisa sobre a existência de possível(is) identidade(s) lésbica(s)/gay(s), e eles demostraram acreditar que não há apenas uma identidade relacionada a lésbicas/gays, apontando a existência de uma pluralidade de identidade(s). Tal percepção está em consonância com as concepções pós-modernas sobre identidades fluidas, vistas como em constante (re)transformação e (re) construção.

Alguns sujeitos de pesquisa demonstraram identificar-se com certas identidades e outros não conseguiram inserir-se em apenas uma caixinha, pois, como as identidades

30 “[ [... ] styles in speaking involve the ways speakers, as agents in social (and sociolinguistic) space, negotiate their positions and goals within a system of distinctions and possibilities". 
são mutáveis, às vezes eles performam uma identidade e outras vezes performam outra. A maioria das duplas apontou que se sente confortável perto de outros sujeitos LGBT ou de pessoas íntimas. Também se investigou a percepção dos sujeitos de pesquisa acerca da fala como marcador de estilo e identidade(s) lésbica(s)/gay(s), e todos consideram que a fala pode sim funcionar dessa forma.

Sobre usos linguísticos característicos do universo LGBT, todos os sujeitos de pesquisa concordam com a existência desses usos e ainda apontam diversos exemplos. Portanto, a partir dessa confirmação, pode-se dizer que esses usos compõem um estilo de fala lésbica/gay. Sobre os fatores contextuais que poderiam propiciar esses usos, os sujeitos apontam o interlocutor e o contexto como fatores principais. Segundo eles, é necessário um interlocutor que seja íntimo e que entenda as palavras e expressões da comunidade LGBT, além de um contexto favorável para a realização desses usos.

Também foram analisadas as formas de referência a lésbicas/gays, e os sujeitos de pesquisa apontaram usos como viado, lésbica e sapatão para referir-se a outros sujeitos homossexuais. Sobre a apropriação e ressignificação de usos linguísticos do universo LGBT por sujeitos heterossexuais, todos os sujeitos de pesquisa avaliaram negativamente esses usos.

Para trabalhos futuros, é pertinente investigar as percepções de lésbicas/gays sobre outros assuntos que lhes concernem, como vivências de preconceito, processo de descoberta/aceitação da orientação sexual etc. Também seria interessante gravar esses sujeitos em diferentes situações/contextos, para analisar como suas falas se adequariam em diferentes ambientes.

\section{Referências}

AUSTIN, J. Quando Dizer é Fazer: Palavras e Ação. Porto Alegre, Artes Médicas, 1990 [1962]. Tradução Danilo Marcondes.

BARROSO, R. R. Pajubá: o código linguístico da comunidade lgbt. Dissertação (mestrado). Universidade do Estado do Amazonas. Programa de Pós-Graduação em Letras e Artes - Manaus. 2017.

BELSEY, C. Critical practice. London: Methuen. 1980.

BENTES, A. C.; FERREIRA-SILVA, B.; MARIANO, R. D. Atenuação e impolidez como estratégias estilísticas em contexto de entrevista televisiva. Cadernos de Letras da UFF, v. 23, n. 47, 2013.

BORBA, R. A linguagem importa? Sobre performance, performatividade e peregrinações conceituais. Caderno Pagu. 2014, n.43, p. 441-474. Disponível em: http://dx.doi. org/10.1590/0104-8333201400430441. Acesso em: 20/12/2018. 
BUTLER, J. Problemas de gênero: feminismo e subversão da identidade. Tradução AGUIAR, R. Rio de Janeiro: Civilização Brasileira, 2003 [1990].

COUPLAND, N. Style: Language variation and identity. Cambridge, UK: Cambridge University Press, 2007.

DRUMMOND, R.; SCHLEEF, E. Identity in variationist sociolinguistics. In: The Routledge handbook of language and identity. Routledge, p. 76-91, 2016.

ECKERT, P.; MCCONNELL-GINET, S. Think practically and look locally: Language and gender as community-based practice. In: Annual Review of Anthropology, p. 461-90, 1992.

ECKERT, P. Variation, convention, and social meaning. In: Annual Meeting of the Linguistic Society of America. Oakland CA. 2005.

ECKERT, P. Communities of practice. In: Encyclopedia of language and linguistics, v. 2, p. 683-685, 2006.

ECKERT, P. Variation and the indexical field. Journal of sociolinguistics, v. 12, n. 4, p. 453476, 2008.

ECKERT, P. Three waves of variation study: the emergence of meaning in the study of sociolinguistic variation. Annual Review of Anthropology, n. 41, p. 87-100, 2012.

ECKERT, P. Variation, meaning and social change. Sociolinguistics: theoretical debates, p. 69-85, 2016.

FELIX, R. A. A. Adjetivo superlativo na fala de homens gays: uma discussão sociolinguística. Dissertação (Mestrado). Universidade Estadual Paulista "Júlio de Mesquita Filho". Programa de Pós-Graduação em Linguística e Língua Portuguesa. 2016.

FOUCAULT, M. História da sexualidade I: A vontade de saber. Tradução ALBUQUERQUE, M. T. C; ALBUQUERQUE, J. A. G. Rio de Janeiro: Edições Graal, 1988 [1999].

JUNG, C. G. Memórias, Sonhos e Reflexões. Compilação JAFFÉ A. Rio de Janeiro, Editora Nova Fronteira, 1975.

GOFFMAN, E. The Presentation of Self in Everyday Life. Nova York, Anchor Books, 1959.

HALL, S. A identidade cultural na pós-modernidade. Rio de Janeiro. DP\&A, 2006.

IRVINE, J. Style as distinctiveness: The culture and ideology of linguistic differentiation. In: ECKERT, P.; RICKFORD, J. R. (Ed.). Style and sociolinguistic variation. Cambridge: Cambridge University Press, 2001.p. 21-43.

JOSEPH,J. E. Historical perspectives on language and identity. In: The Routledge handbook of language and identity. Routledge, 2016. p. 45-59.

KIESLING, S. F. Constructing identity. In CHAMBERS, J. K.; SCHILLING, N. (Ed.) The handbook of language variation and change. $2^{\text {a }}$ ed. Oxford, U.K.: Blackwell, 2013. p. 448-467. 
LABOV,W. The socialstratification of English in New York City. 2 ed. Cambridge: Cambridge University Press. 2006 [1966].

LANZ, L. O corpo da roupa: a pessoa transgênera entre a transgressão e a conformidade com as normas de gênero. Dissertação (Mestrado). Universidade Federal do Paraná. Curso de Pós-Graduação em Sociologia. 2014.

LAU, H. D. Será que toda "mona" fala "bichês"? A questão da linguagem e identidade da comunidade LGBT. Temática, v. 13, n. 3, 2017.

MENDES, R. B. Diminutivos como marcadores de sexo/gênero. Revista Linguística, v. 8, n. $1,2012$.

RAMPTON, B. Continuidade e mudança nas visões de sociedade em linguística aplicada. In: MOITA LOPES, L. P. (Org.). Por uma linguística aplicada INdisciplinar. São Paulo: Parábola Editorial, 2006.

RIBEIRO, D. O que é: lugar de fala? Belo Horizonte (MG): Letramento, 2017.

ROSA, N. G.; LUCENA, A. F.; CROSSETTI, M. G. O. Etnografia e etnoenfermagem: métodos de pesquisa em enfermagem. Revista Gaúcha de Enfermagem. Porto Alegre. Vol. 24, n. 1, p. 14-22, 2003.

SANTANA, W. P. S. Variação de gênero gramatical como indexador de identidade gay. Dissertação (Mestrado). Universidade Federal de Santa Catarina. Programa de PósGraduação em Linguística - Florianópolis. 2018.

VALLE, C. R. M. Multifuncionalidade, mudança e variação de marcadores discursivos derivados de verbos cognitivos: forças semântico-pragmáticas, estilísticas e identitárias em competição. Tese (Doutorado). Universidade Federal de Santa Catarina. Programa de Pós-Graduação em Linguística - Florianópolis. 2014.

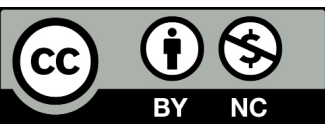

Data de submissão: $31 / 08 / 2020$

Data de aceite: 30/09/2020 